\title{
MOBİL DİL ÖĞRENME OYUNU UYGULAMALARININ TASARIMINDA VE SEÇIMIINDE KULLANILABİLECEK ÖLÇÜTLER ÜZERİNE BİR ALAN TARAMASI ÇALIŞMASI
}

\section{Harun GÖÇERLER*}

Makale Geliş Tarihi-Received: 22.01.2021

\section{ÖZ}

Günümüzde yabancı dil öğrenicileri, kendi dil becerilerini desteklemek amacıyla dijital imkânlardan çokça faydalanmaktadır. Bu noktada mobil dil öğrenme oyunu uygulamaları öğreniciler için eğlenceli bir alternatif olarak görülmektedir. Sayıları günden güne artan bu uygulamalardaki çeşitlilik, aynı zamanda bir nitelik sorununu da beraberinde getirmektedir. Söz konusu uygulamalarn kullanıma sunulduğu platformların neredeyse bir uygulama çöplüğ̈̈ haline gelmesi sebebiyle, dil becerilerinin gelişimine katkı sağlayabilecek etkili bir mobil uygulama seçebilmek tüm kullanıcılar tarafindan dikkate alınması gereken bir unsurdur. Bu çalışmada mobil dil öğrenme oyunu uygulamalarının geliştirilmesi ve seçimi konusunda bir alan yazın taraması yapılmıştır. Bu sayede ülkemizde geliştirilme potansiyeli olan mobil dil öğrenme uygulamalarnn niteliksel özelliklerinin gelişiminde katkıda bulunmak hedeflenmiştir. Sonuç kısmında söz konusu uygulamaların kullanıcıya sunması gereken ana başlıklar şu şekilde sıralanmıştır; mobil dil öğrenme oyunu uygulamasının kullanıcısı için ilgi çekici görünüm ve içerik özelliklerinin olması gerekir, oyunsal özellikleri ile farklı kullanıclar ya da sanal kullamıcı ile rekabeti mümkün kılabilmesi gerekir, dil öğrenmekte olan

* Dr. Öğr. Üyesi, Tekirdă̆ Namık Kemal Üniversitesi, Fen-Edebiyat Fakültesi, Alman Dili ve Edebiyatı Bölümü, Değirmenaltı Kampüsü, Tekirdă̆/Türkiye. hgocerler@nku.edu.tr, ORCID: https://orcid.org/0000-0002-2394-3795. 


\section{Harun GÖÇERLER}

kullanıcının oyun kurgusu içerisinde yeni bilgiler araştırabilmesi ve oyundaki mekânlarda serbestçe gezebilmesi gerekir. Bu noktalar haricinde kullanıcıların dil gelişimine yönelik ihtiyaçlar ile psikolojik gelişim düzeyinin de oyunu oynamaya uygun olmasının önemine vurgu yapılmıştır. Ayrıca bu çalışmada aktarılan ölçütlerin belirleyici kesin ölçütler olmadığı, fakat dil eğiticileri tarafindan temel alını konuya, öğreniciye, güçlendirilmek istenen dil becerisinin niteliğine göre yeniden şekillendirilebileceğ $i$ anımsatılmıştır.

Anahtar Kelimeler: Mobil Dil Öğrenme, Akıllı Telefon Uygulamaları, Dijital Öğrenme, Oyun Uygulamaları, Kesintisiz Öğrenme. 
Mobil Dil Öğrenme Oyunu Uygulamalarının Tasarımında ve Seçiminde Kullanılabilecek Ölçütler Üzerine Bir Alan Taraması Çalışması

\title{
A FIELD STUDY ON THE CRITERIA TO BE BENEFITTED FROM IN THE DESIGN AND SELECTION OF MOBILE LANGUAGE LEARNING GAME APPLICATIONS
}

\begin{abstract}
Mobile language learning game applications are a fun alternative today, as learners must use digital facilities to support their language skills. The diversity in these applications brings out a quality problem. Since these applications' platforms have become an application dump, choosing a practical mobile application to improve language skills has become a crucial factor. In this study, a literature analysis on the subject has been conducted, and the points that may be useful in the design and selection of mobile language learning games have been determined in general. The three prominent headings are as follows: Firstly, the application needs an interesting appearance and quality content features. Secondly, it needs to enable competition with different users. Thirdly, it needs to arouse curiosity for information and enable users to navigate freely in the game. Apart from these, the target audience's language and psychological development necessities are emphasized. In the conclusion part, it is reminded that the criteria conveyed in this study are not definitive, but they can be taken as a basis by educators and reshaped according to the subject to be taught and the skill to be strengthened.
\end{abstract}

Keywords: Mobile Language Learning, Smartphone Apps, Digital Learning, Game Apps, Continuous Education. 
Harun GÖÇERLER

\section{GİRiş}

Web 2.0 uygulamaları, mobil cihazlar ve internetin hayatın içinden öğeler olarak görüldüğü çağımızda, bu üç kavram etrafında şekillenen teknolojik gelişmelerin eğitim bilimleri alanından ayrı görülemeyeceği aşikârdır. Bilgisayarın ve internetin çok yaygın bir şekilde hayatımıza nüfuz ettiği zamandan bu yana html, Pixel, Java, Word Wide Web (www), indirme, yazılım, çevrim içi programlar, dokunmatik ekran, akıllı tahta, akıllı telefon, tablet bilgisayar, eöğrenme, M-öğrenme, çevrim içi öğrenme, medya pedagojisi, medya kullanım yetisi, çoklu medya, dijitalleşme, sanal gerçeklik, e-kitap, mobil uygulamalar vb. kavramlar artarak hayatımızın tüm anlarını farkında olarak ya da olmadan etkilemeye başlamıştır. Bu gibi yeni ortaya çıan ve zamanla yenilenen kavramların kullanımının günlük aktivitelerimizi yönlendirir düzeye gelmiş olması sebebiyle, günümüzde bilgiye erişim eskiye nazaran daha zahmetsiz bir hal almıştır.

Örneğin yukarıda anılan kavramların kendini dil eğitiminde uygulama boyutunda gösteriş biçimlerinden biri olan kesintisiz öğrenme (Seamless Learning) olgusu, öğreniciler arasında sınıf içinde ve dışında birlikte çalışmayı teşvik eden bir yöntem halini almıştır. Kesintisiz öğrenme yöntemi, nihai öğrenme hedefine ulaşmak için sürekli iletişimde kalarak farklı teknolojik imkânları kullanmanın olağan hale geldiği bir birlikte öğrenme şekli olarak alan yazında araştırma konusu olmuştur (bkz. Specht vd., 2013). Burada sözü edilen imkânlar arasında yer alan araçlar, öğrenicinin her an iletişimde kalabilmesini sağlayacak kullanım konforuna sahip olma özelliğini taşımalıdır (Biebighäuser, 2015: 3). Specht, Ebner ve Löcker'e göre de zaman ve mekândan bağımsız öğrenmeyi destekleyecek araçların kesintisiz iletişimi temin edecek özellikte olması ve farklı öğrenme uygulamalarının kullanımında teknik aksamalara yol açmaması önemli bir unsurdur (bkz. 2013). Özellikle etkili bir sınıf dışı öğrenme, bu araçların sunduğu imkânların etkin kullanımı ile desteklenebilir.

Bu düşüncelerden yola çıkarak özellikle dil öğrenicilerinin farklı dil becerilerini desteklemek amacıyla yazılmış mobil uygulamaların kullanımının mobil cihazlar tarafından sorunsuz bir şekilde sağlanabiliyor olması, dil öğrenen kişinin kendi başına zaman ve mekândan bağımsız bir şekilde öğrenim sürecini desteklemesinde 


\section{Mobil Dil Öğrenme Oyunu Uygulamalarının Tasarımında ve Seçiminde Kullanılabilecek Ölçütler Üzerine Bir Alan Taraması Çalışması}

faydalı olabilir. Fakat tabii ki tek husus kullanılan mobil cihazın teknik özelliklerinin yeterliliği değildir.

2012 yılından bu yana incelenen PISA-Araştırması sonuç raporlarına da bakılacak olursa Türk öğrencilerin, genel olarak öğrenim süreçlerinde bilgisayar ve taşınabilir iletişim cihazlarına gün geçtikçe daha da fazla başvurduğu görülmektedir (Anıl vd., 2015: 163). Bu sonuç, öğrenicilerin diğer alanlarda olduğu gibi dil öğrenim süreçlerinde de söz konusu cihazlara ve dolayısıyla bir takım mobil uygulamaların kullanımına eğilim gösterebilecekleri yorumunu beraberinde getirir. Sonuç olarak öğrenicilerin dil öğrenimini destekleme hedefinde olan mobil uygulamaların nitelik açısından belirli bir standardın altında olmaması, kullanılan cihazın teknik yeterlilikleri kadar önemlidir.

Bu küçük örnekten hareketle bu çalışmada asıl ele alınmak istenen husus, mobil dil öğrenim uygulamalarının oluşturulması öncesinde, esnasinda ve kullanımı sırasında kullanıcıya sunulması gereken kullanım konforu, uygulamaların öğrenmeye motive ediciliği, kullanıcıya görelik ilkesi vb. noktalarda göz önünde bulundurulması gereken bir takım ölçütlerin alan yazın taraması yapılarak ortaya konmasıdır. Bu sayede mobil dil öğrenim uygulaması geliştiricilerine dil eğiticisi gözünden de sşık tutmak hedeflenmiştir. Nitekim hali hazırda ücretli ve ücretsiz olarak kullanımda olan mobil dil öğrenme uygulamalarının çoğunda yapısal ve içeriksel nitelik sorunları olabileceği göz ardı edilmemelidir.

Çalışmanın bundan sonraki bölümlerinde mobil uygulamaların ne olduğu, ortaya çıkış süreci ve genel niteliği tanıtılacak, ardından mobil dil öğrenme oyunu uygulamalarının dil öğrenimine yansımaları ele alınacaktır. Bir sonraki bölümde ise uygulama geliştirme ve seçme aşamalarında yön gösterici bir ölçüt olarak görüldüğünden dolayı, mobil dil öğrenme oyunu uygulaması kullanıcılarının genel özelliklerine değinilecektir. Çalışmanın sonuç kısmından önce, mobil dil öğrenme oyunu uygulamalarının sahip olması gereken temel nitelikler siralanacak ve siralanan niteliklerin öğretici, öğrenici, uygulama geliştiriciler açısından faydalarına değinilmeye çalışılacaktır. 


\section{MOBİL UYGULAMALAR}

Bilgi iletişim teknolojileri kavramı düşünüldüğünde, akla ilk gelen terimlerden birisi neredeyse akıllı telefonların yaygın olarak kullanıma sunulmasina paralel bir zamanda taninır hale gelen "dokunmatik ekran" terimi olmaktadır. Dokunmatik ekran teknolojisinin gelişimine paralel olarak okuma, yazma, dinleme gibi aktiviteler avuç içerisine sığan günlük aktiviteler olarak hayatın sıradan parçaları haline gelmiş (Grüner, Hassert, 1992: 42) ve gelişen / gelişmekte olan ülkelerde insanların büyük kısmının bir ekrana dokunmadan gün geçirmesi olağan dışı sayılmaya başlamıştır. Söz konusu topluluğun aslen mobil cihazların ekranı başında bilgi edinme amacıyla olmadıkları bilinmekle beraber (vgl. Stieglitz vd., 2013: 50), bu durum zaman içinde değişime uğramaya başlamıştır. Dolayısıyla günümüzde eğitimi alınan alanda detaylı çalışmalar yapmak amacıyla da ekranlara dokunmanın hızla bir alışkanlık haline gelmekte olduğu görülmektedir. Nitekim çağımızda insanlar dokunmatik ekrana sahip çoklu medya özelliği olan cihazları öğrenme, çalışma, sohbet etme, oyun oynama, araştırma yapma, okuma yazma, iletişim kurma, fotoğraf ve video çekme, dijital resimler yapma, kısa filmler çekme, video konferanslara katılma ve hatta bu yaptıklarını sosyal paylaşım siteleri üzerinden başkaları ile de paylaşmayı alışkanlık haline getirir oldu (bkz. Yücel vd., 2015: 270).

Tabii ki bu basit gibi görünen aktiviteleri yapmak, özel bir takım yazılımlar olmadan mümkün değildir. İşte bu yazılımlara İngilizce' den devşirilmiş adı ile "aplikasyon", Türkçe' deki karşılığı ile "mobil uygulamalar" ya da "akill telefon uygulamaları" denmektedir. Uygulama kelimesi, akıllı telefonlardaki programların işlemesi için gerekli olan yazılım olarak hafızalara yerleşmiş olsa da aslen bilgi iletişim teknolojileri alanında kullanılan tüm programların içeriğini kapsamaktadır (bkz. Bach, 2012: 21; bkz. Willers, 2013: 14). Yani birçok uygulama Windows işletim sistemleri ile çalışan masa üstü bilgisayarlar, laptoplar, notbooklarda da kullanılmaktadır (bkz. Biebighäuser, 2015: 2). Bu cihazlarda kullanılan uygulamalar genel olarak metin yazma, hesaplama yapma, veri kaydı tutma gibi özellikleri ile günlük hayatı kolaylaştırmayı amaçlamaktadır. $\mathrm{O}$ yüzden bu tür ilk nesil uygulamaları klasik uygulama yazılımları adıyla anmakta sakınca yoktur. Simon Falk (2015: 15) akıllı telefon uygulamalarını bilgisayar programlarından ayıran tek farkın işletim 


\section{Mobil Dil Öğrenme Oyunu Uygulamalarının Tasarımında ve Seçiminde Kullanılabilecek Ölçütler Üzerine Bir Alan Taraması Çalışması}

sistemlerinin üstlendiği görevlerin farklı oluşundan kaynaklandığını dile getirmektedir.

Fakat bir diğer yaygın görüşe göre ise uygulama kelimesinden çıkarılması gereken asıl mana, sadece mobil cihazlar ve tablet bilgisayarlar için üretilen yazılımlar olarak düşünülmelidir (Kohring, 2014: 5). Esasen bu çalışmada da temel olarak bu yorum üzerinde fikir yürütülmeye çalışılacaktır. Johnson vd. yaptığı araştırma bu görüşün temel alınmasında etkili olmuştur. Öyle ki; Johnson, Adams ve Cummins (2012: 11) bir piyasa analizi şirketi olan ABI'in verilerinden alıntıladığ 1 makalesinde 2011 Ocak ayı itibariyle Apple Store'dan 18 milyardan fazla ve aynı yılın aralık ayına kadar ise Android işletim sistemine sahip diğer platformlardan 10 milyardan fazla mobil uygulama indirildiğini tespit etmiştir. Bu sayının 2021 yılı itibariyle net karşılığını bulabilmek oldukça güç olsa gerek. Bu rakamlar, söz konusu teknolojinin ekonomik değerinin büyüklüğü yanında akıllı telefonların kullanım alanlarının ne derece artmakta olduğunu da göstermektedir.

Simon Falk (2015: 15) bir araştırmasında 2015 yılında sadece iOS AppStore platformunda en az 24 farklı kategoride mobil uygulama bulunduğunu dile getirmiştir. Aynı araştırmada bu kategorilerin her birinin birçok alt kategorisi olan mobil uygulamalar bulunduğunu da belirtmiştir. $\mathrm{Bu}$ veriye Google Play-Store platformu eklendiğinde sayının artması kaçınılmaz olacaktır.

Yukarıdaki verilerden yola çıkarak, dil öğrenimi - öğretimini alanında da başvurulan mobil uygulama sayısının azımsanmayacak kadar fazla olduğu düşünülebilir. Dolayısıyla bu aşamada söz konusu mobil dil öğrenme uygulamalarının kurgusal olarak en temel özelliklerine değinmekte fayda görülmektedir. Aşağıdaki şekil, mobil dil öğrenme uygulamalarının dil eğitimi alanında zamandan ve mekândan bağımsız öğrenme özgürlüğünün döngüsünü somut bir şekilde ortaya koymaktadır. 


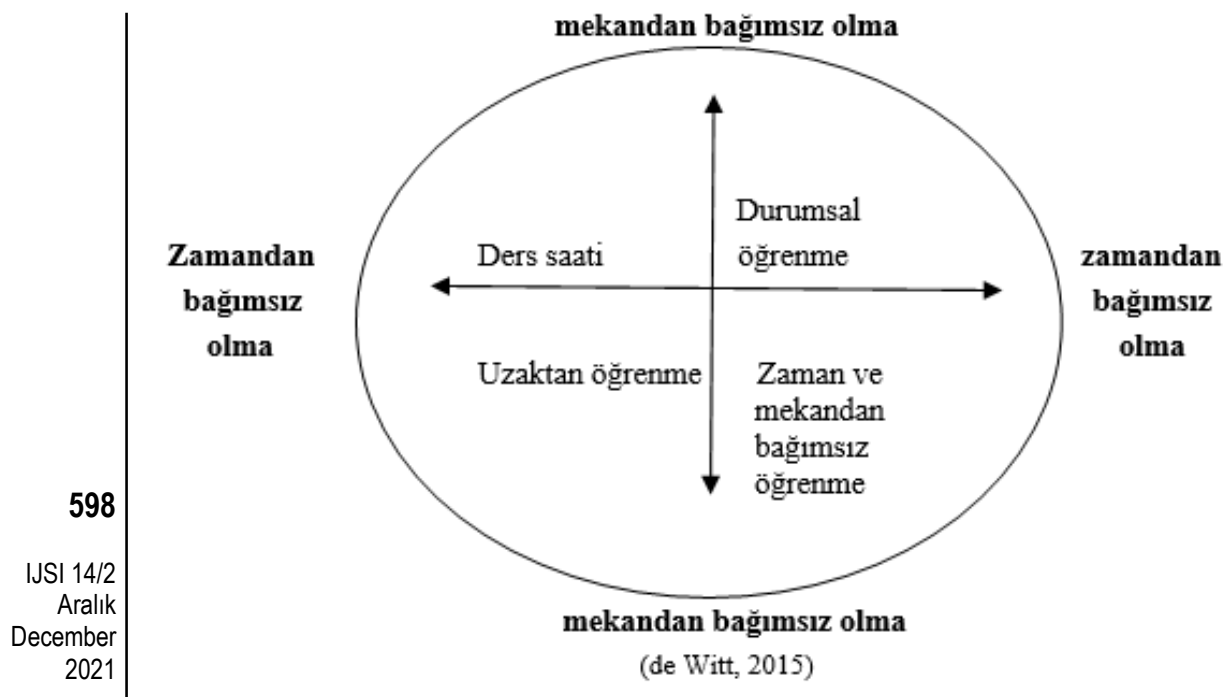

Şekil 1: Mobil uygulamaların genel karakteri

Şekilden de anlaşılacağı üzere mobil uygulamalar sayesinde şimdiye dek öğrenme süreçlerinde genel belirleyiciler olan öğrenme mekânı ve öğrenen kişinin ders ortamındaki mevcudiyeti, mobil akıllı telefon uygulamaları sayesinde yeni bir anlam kazanmış ve yeniden şekillenmiştir (bkz. Kolef, Rieder, 1999: 25). Bu durum özellikle dil öğrenicileri açısından ders ortamı dışındayken yanında destek materyalleri taşıma, sözlük taşıma, sayfalarca fotokopi alıştırmaları taşıma gibi durumları da ortadan kaldırmasıyla yeni öğrenme yollarının keşfedilmesine kapı aralamaktadır.

Giemza'nın tespitine göre de artık dil öğrenme aşamalarında öğreniciler, öğrenme alıştırmalarının büyük bölümünü alışıla gelmiş sınıf ortamının dışında gerçekleştirmeyi tercih etmekteler. Genelde boş zamanlarında, otobüste yada yapacak başka bir işleri olmadığında mobil dil öğrenme uygulamalarından kelime alıştırması çözmeyi denemekteler (Giemza vd., 2012: 255). Giemza'nun bu tespiti temelde öğrenicilerin yapmaktan zevk aldıkları aktiviteleri kendilerini en serbest hissettikleri ortamlarda gerçekleştirme eğiliminde olabileceklerini göstermektedir.

Mobil dil öğrenme uygulamaları bu düşünceden hareketle irdelenecek olursa, bu uygulamaların genel olarak zamanı eğlenceli 


\section{Mobil Dil Öğrenme Oyunu Uygulamalarının Tasarımında ve Seçiminde Kullanılabilecek Ölçütler Üzerine Bir Alan Taraması Çalışması}

bir şekilde geçirtmeye odaklı özelliklere sahip olmasından dolayı dil öğrenenleri öğrenmeye teşvik edebileceği söylenebilir. Nitekim sayısız akıllı telefon uygulaması ya temelde bir oyun üzerine kurgulanmıştır ya da oyunsal öğeler içermektedir (Gabriel, 2013: 259). Kohring (2014: 5), bir piyasa araştırması şirketi olan Canalys'in sonuçlarına dayandırdığı bir çalışmasında 2012 yılında ekonomik gelir hedefleyen uygulamaların \% 83'ünün oyun temelli olduğunu belirtmiştir.

Ostmeier'in (2002: 184) görüşüne göre gençlik bilgisayar oyunlarında, akıllı telefon oyunlarında ve kendi kurduğu sanal dünyasında topluluk hissini yaşar, dikkat toplamada destek alma ihtiyacını karşılar. Ayrıca derste yada gerçek dünyada alamadığı terapi yardımını alır, bu şekilde zihnini rahatlatır. Esasen birçok dil öğretim mecrasında ders kitabının bir parçası olan kitaba özgü dil öğrenme oyunu uygulamaları mevcut olsa da, birçok dil öğreticisi öğrencilerine formal eğitimden bir nebze de olsa uzaklaşmış ve kendilerini özgür hissetmeleri amacıyla kitaptan bağımsız mobil dil öğrenme oyunu uygulamaları tavsiye etmektedir (bkz. Skoularioti, 2013: 20). Trip Wire Magazin'in araştırması da bu görüş ve yöntemi destekler niteliktedir. Nitekim 2010 yılında 9 milyon, 2011 yılında ise 61,9 milyon insan çevrimiçi sosyal oyunlara katılmıştır. Bu oyuncuların \%40'1 20 ila 34 yaşları aralığında olan genç kullanıcılardan oluşmaktadır (Johnson vd., 2012: 21). Bu sonuçlara göre gençlerin bakış açısından sosyalleşmenin ve kendini öğrenme yolunda özgür hissetmenin yollarından birinin de sanal dünyada oynanan oyunlar olduğu şeklinde yorumlanabilir. Tüm bu noktalardan hareketle bu çalışmanın temel yönlendirici öğesinin genel olarak mobil uygulamalar değil, mobil dil öğrenme oyunu uygulamaları olmasında fayda görülmüştür.

Bu görüşe dayanarak genç insanların öğrenme, araştırma yapma, öğrenileni tekrar etme, alıştırma çözme vb. noktalarda dijital öğrenme etkinliklerine tereddütle yaklaşmayacağ 1 ön görülebilir. Özellikle mobil dil öğrenme oyunu uygulamaları gençler için öğrenmekte oldukları dili kullanmaya teşvik edici ve motive edici bir faktör olabilir. Mobil dil öğrenme oyunu uygulamalarının bir alt kategorisi olan konu odaklı ciddi oyunlar (serious games) derslerde ele alınan konuları ders dışında farklı bir açıdan desteklemek amacıyla programlandıklarından dolayı, dil öğrenen kişiler için önemli bir destek ögesi olarak kullanılabilir. 
$\mathrm{Bu}$ sebepten gençlerin büyük çoğunluğunun zamanının önemli kısmını akıllı telefon ekranı karşısında geçiriyor olması garipsenecek bir durum değil, aksine onların eğitimi açısından da faydalanılabilecek yönlerinin ortaya çıkarılması gereken bir olgudur. $\mathrm{Bu}$ görüşten yola çıarak genç yabancı dil öğrenicilerinin, kullanıcısının gereksinimlerine hitap eden mobil dil öğrenme uygulamalarındaki oyunlardan zevk alması muhtemeldir. Çünkü telefon ekranı karşısında uzun süreler zaman geçirme durumu ilk nesil cep telefonlarının ortaya çıkısıından bu yana gözlenen ve özellikle gençler arasında yaygın olan bir alışkanlık halini almıştır. $\mathrm{Bu}$

durumda belli yaş grubundaki kişilerin eski alışkanlıklarından zamanla vazgeçmedikleri, aksine kullanım imkânları bağlamında çeşitlilik sunan daha da gelişmiş, grafik animasyonları çeşitlenmiş oyunlar ile bu alışkanlığın günlük rutinlerden biri haline geldiği bile söylenebilir. Aynı durum özelde daha önceleri sadece masa üstü bilgisayarlarda kullanılabilen mobil dil öğrenme oyunlarının kullanımı için de geçerlidir. Günümüzde sayısız dil öğrenme oyunu ücretli ve ücretsiz, çevrimiçi ve çevrimdışı olarak istenilen her an ulaşılabilir durumdadır.

Konuyu dil öğrenimi - öğretimi açısından daha yakından ele almak için bir sonraki kısımda mobil dil öğrenme uygulamalarının dil öğrenimi içerisindeki rolü irdelenecektir.

\section{MOBIL DIL ÖĞRENME OYUNU UYGULAMALARININ DIL ÖĞRENIMINE YANSIMALARI}

Eğitim bilimleri alanında, içeriğinde genel olarak öğretim ve öğrenim süreçlerini kolaylaştırıcı nitelikte uygulamaların kullanımını da teşvik edici birçok dil öğretim metodu ve yöntemi çoktan yerini almış olmasına rağmen, dil öğretim ve öğrenimi alanında taşınabilir cihazların ve özellikle dil becerilerinin geliştirilmesine odaklı mobil uygulamaların 2010 yılından itibaren ağırlık kazandığı görülmektedir (bkz. Stieglitz vd., 2013: 50). Stieglitz vd. Almanya'da iki farklı üniversitede eş zamanlı yaptığı çalışmada, öğrenicilerin derslerine destek amaçlı temel başvuru aracı olarak mobil medyaları tercih ettiklerini (bkz. 57) ve bu medyalardan yararlanmayı bir ihtiyaç olarak gördüklerini tespit etmiştir. Biebighäuser'e (bkz. 2015: 3) göre ise mobil uygulamalar, taşınabilir ve içeriği aktarılabilir olduğu için yabancı dil derslerinde mobil öğrenme yöntemi ile ilgili tartışmaların 


\section{Mobil Dil Öğrenme Oyunu Uygulamalarının Tasarımında ve Seçiminde Kullanılabilecek Ölçütler Üzerine Bir Alan Taraması Çalışması}

önemli bir bölümünü oluşturmaktadır. Stieglitz'in araştırmasında yer alan denekler arasında taşınabilir medya gereçleri ve uygulamalarının tercih edilmesinin muhtemel sebebi de bu olabilir.

Bu yüzden, akıllı telefon teknolojisi geliştikçe öğrenme ve öğretim içeriklerinin de grafik, görsellik, çok boyutluluk etkenleri etrafında şekillendiği içeriklerin akıllı telefon uygulamalarında da vücut bulur hale geldiği görülmektedir. Özellikle ders içeriklerinin dil öğrenme oyunu uygulamalarında şekil değiştirerek vücut bulması, bilginin uzun süreli hafızaya aktarılması ve öğrenmeyi kolaylaştırıcı desteklerden biri olabileceği düşüncesi zamanla alan yazında sıkça dile getirilmeye başlanan bir görüş halini almıştır (bkz. Skoularioti, 2013: 5).

Akıllı telefon uygulamalarının bu özelliği dil öğrenici ve öğreticilerinin de dikkatini çekmeye başlamıştır. Dolayısıyla mobil dil öğrenme oyunu uygulaması geliştiriciler, söz konusu kitleden gelen taleplere cevap verebilmek amacıyla dil öğrenimi özelinde ilk olarak klasik flash kartları, sözlükleri, dinleme materyallerini, dil öğrenme oyunlarını, alıştırmaların eşlik ettiği metinleri yazarlık sistemleri temelli web destekli çevrim içi yabancı dil öğrenim portallarına dönüştürmüştür. Elde edilen sonuçlardan hareketle de benzer içerikleri akıllı telefon ve tablet bilgisayarlar aracılığı ile küçük dil öğrenme uygulamalarında kullanıma sunmaya çalışmıştır. Bu çalışmalar neticesinde öğrenme sürecinin öğreniciler açısından daha motive edici ve eğlenceli hale büründüğü görüldükçe, dil öğreticilerinin de kendi öğretim materyallerinde bir takım dijital yenilikler yapmalarına zemin hazırlanmıştır denebilir (bkz. Alyaz, 2005). Dil öğreticilerinin, ders içeriklerini destekleyici bir unsur olarak gördükleri başvuru araçlarından biri de mobil dil öğrenme oyunu uygulamalarıdır.

Bu noktada önemli olanın, öğrenenlerin kullanımına sunulacak olan mobil dil öğrenme oyunu uygulamalarının hangi ölçütler doğrultusunda şekilleneceğinin doğru tespit edilmesi olduğu düşünülmektedir. Çünkü Biebighäuser'e (2015: 5) göre kullanımda olan mobil dil öğrenme oyunu uygulamalarının geneli aslında bol tekrara dayalı, kullanıcıyı rekabete sürüklemekten uzak olan klasik dil öğrenme materyallerinin ve alıştırmalarının birer dijital kopyası olmaktan ibarettir. 
Söz konusu olan, dil öğrenimi olduğu için ilk bakışta ilgi çekicilik ile başlayan, uygulamayı kullanıma ve içeriği öğrenmeye yönelik motivasyon ile devam eden ve en nihayetinde başvurulan uygulama ile dil öğrenme sürecinin desteklenebilmiş olmasından zevk alma ile biten bir süreç ortaya çıkması beklenmektedir. Dolayısıyla geliştirilecek olan mobil dil öğrenme oyunu uygulamalarının gelişi güzel değil de anılan bu sürece yönelik olarak da içeriksel yapılara sahip olması etkili bir dil öğrenme destekleyicisi olma yolunda uygulamanın başarısına ve öğrenenin faydalanmasına katkı sağlayacaktır. Biebighäuser'e (bkz. 2015: 8) göre ders dışında işe koşulan mobil öğrenme uygulamalarının, özellikle de dil öğrenme

Tüm öğrenme süreci içerisinde asıl olan nokta seçilen uygulamadan faydalanması hedeflenen kullanıcılar olduğu için bir sonraki bölümde mobil dil öğrenme oyunu kullanıcıları konusu ele alınacaktır.

\section{MOBILL DIL ÖĞRENME OYUNU UYGULAMASI KULLANICILARI}

Program geliştiriciler ve yayınlayıcı platformlar bir mobil dil öğrenme oyunu uygulamasını satış platformlarında sunmadan önce, ortaya çıkacak olan oyun uygulamasının potansiyel kullanıcıların ilgisini cezbetmesi amacıyla oyun içeriklerinin yapılandırılması ve grafik görsellerin oluşturulması aşamasında kullanıcıyı oyunu oynamaya ikna edici hangi (persuasiv) elementlerin ya da araçların kullanılması gerektiğini göz önünde bulundurmaktadır. Bu noktada oyun uygulamasının yapılandırılması aşamasında insan davranışlarını mercek altına alan iki model öne çıkmaktadır.

Fogg'un (bkz. 2009) modeli insanın bir davranış sergilerken (bu çalışma özelinde dil öğrenme uygulaması seçerken sergilenen davranışlar) etkisi altında kaldığı üç ana faktörü ele almıştır. Bu davranış modeline göre kişilerin bir eyleme geçmek için kendilerini uygulamayı kullanmaya motive eden bir sebebi olmalıdır. İkinci 


\section{Mobil Dil Öğrenme Oyunu Uygulamalarının Tasarımında ve Seçiminde Kullanılabilecek Ölçütler Üzerine Bir Alan Taraması Çalışması}

olarak, kişinin bir şeyi başaracak yeterlilikte olduğuna dair hislere sahip olduğunu görmesidir. Akabinde kişiyi eyleme geçmeye itecek bir olay, hedef ya da çözülmesi gereken bir sorun olmalıdır. Burada bahsi geçen harekete geçirici unsur, motivasyon ve dil kullanım becerisinin bir karışımı olarak görülebilir.

Fogg'a göre, bir oyun tasarımının uygulamada başarılı olabilmesi yukarıda anılan unsurların birbiri ile iyi yapılandırılmış kombinasyonuna bağlıdır. Fakat yine de asıl kullanıcı, sayısız dil öğrenme uygulaması arasından hangisinin kendi ihtiyaçları için mantıklı bir çözüm olacağı sorusunu kendine soracaktır (Falk, 2015: 17). Bu bakış açısından yola çıkarak Bartles, konuya Fogg'dan daha farklı bir açıdan yaklaşmaktadır. Bartles, bir dil öğrenim uygulaması geliştirme aşamalarında aslen oyuncu tiplemelerinin göz önünde bulundurulması gerektiğini düşündüğü kendi modelini savunmaktadır. Bartles'a göre oynamak için farklı sebepleri olan dört oyuncu tipi vardır.

Tablo 1: Bartles'in modeline göre oyuncu tipleri.

\begin{tabular}{|l|l|}
\hline Başarıya odaklı tip & Dengeli bir oyun oynamak ve olumlu sonuçlar elde etmek ister. \\
\hline $\begin{array}{l}\text { Sosyalleşme } \\
\text { amacında olan tip }\end{array}$ & $\begin{array}{l}\text { Bu tür oyuncular arkadaş bulmak ve oyunda yeni insanlar } \\
\text { tanımak ister. Oyun esnasında diğer oyuncuların onun kendi } \\
\text { dünyasının parçası olduğunu düşünür ve ancak grupça } \\
\text { oynanan oyunlardan tat alır. }\end{array}$ \\
\hline Ezici tip & $\begin{array}{l}\text { Diğer oyuncuları oyun becerileri ile etkilemek, baskı altına } \\
\text { almak ister. Örneğin, diğer oyunculara sürekli oyun } \\
\text { kaybettirmeye çalışır. }\end{array}$ \\
\hline Araştırmacı tip & $\begin{array}{l}\text { Bu oyuncu tipi, oyunun bilinmeyen dünyasını keşfetmeyi ve } \\
\text { oyunun tim gizli şifrelerini, yönlerini araştırıp bulmayı tercih } \\
\text { eder. Oyun oynarken her noktaya odaklanmaya çalışır ve } \\
\text { oyunun nihai hedefine ulaşmayı dener. }\end{array}$ \\
\hline
\end{tabular}

(Oberneder, 2015: 29)

Yabancı dil eğitimi çerçevesinde Fogg ve Bartles'ın fikirleri bir biriyle örtüştürülecek olursa Fogg'un modeli, Bartles'in sosyalleşme odaklı oyuncu tipi ve başarı odaklı oyuncu tipinin özelliklerinin birlikte ele alınması mantıklı olacaktır. Çünkü yabancı dil derslerinde ödev verme ve dersi okul dışında da desteklemek amacıyla bir takım dijital medya ürünleri tavsiye etme ya da aynı hedef ile mobil dil öğrenme oyunu uygulaması tavsiye etme gibi durumlarda başarıya odaklı olma ve yabancı dilde sosyal etkileşimde bulunmayı hedefleme gibi 
faktörler her dil öğrenicisinin de ihtiyaç duyduğu ana hedefler arasındadır.

Tüm bu sebeplerden dolayı çalışmanın ana bölümünü oluşturacak olan bir sonraki başlıkta mobil dil öğrenme uygulamalarının sahip olması gereken temel nitelikler ele alınacak ve anlatılanlardan hareket ile uygulama geliştiricilerin yapacakları çalışmalarda, dil eğiticilerinin seçecekleri uygulamalarda göz önünde bulundurmaları önerilen noktalar açıklanmaya çalışılacaktır.

\section{MOBİL DİL ÖĞRENME OYUNU UYGULAMALARININ SAHIP OLMASI GEREKEN TEMEL NITELIKLER}

Yukarıda aktarılan bilgilere dayanarak, bir oyun ilk olarak oyuncuyu oyun içerisinde bir şeyler keşfetmeye, bir problemi çözümlemeye ve oyun mantığ1 sayesine bir şeyler öğrenmeye movite etmelidir. Oyuncu ancak elindeki oyunun kendine uygun olduğuna inandığında oyundaki hedefe ulaşmak için çaba harcayacaktır. Bu durum aynı zamanda okul içi ve dışı öğrenme süreçlerinde öğreticinin yaptığı planlarda olduğu kadar, mobil dil öğrenme oyunu uygulamalarının tasarımında da göz ardı edilmemesi gereken önemli bir faktördür.

Çünkü bu gibi noktalar göz önüne alındığı sürece öğrenici kendi öğrenme sürecini belirlemeye ve bu yolda kendi başına eyleme geçmeye karar verebilir ya da karara bir adım daha yaklaşabilir. Bu sebepten, bir öğrenme uygulaması olarak mobil dil öğrenme oyunu uygulamalarının bağımsız ve keşfedici dil öğrenme aşamasında klasik dil oyunlarına göre daha az eğitici olduğu söylenemez. Çünkü dijital alt yapıya sahip olan mobil dil öğrenme oyunu uygulamaları, öğrenicinin farklı algı kanallarına hitap eder ve onu oyunun direktifleri ile amaçları hakkında daha detaylı düşünmeye teşvik eder. Tüm bu süreç, öğrenilmesi hedeflenen dilde gerçekleşeceği için, öğrenici oyunda geçen ifadeleri anlamak amaciyla okuma - anlamaya ve dinleme - anlamaya yönelik algılarını sürekli açık tutmaya çalışacaktır.

Strasser (bkz. 2012: 3) günden güne ortaya çıkmakta olan birçok Web 2.0 uygulamasının yoğun bilgi karmaşasını denetlemek, eleyici bir süzgeçten geçirmek ve dil öğrenmeye yönelik faydasını irdelemek için somut uygulanabilir yöntemlere ihtiyaç olduğunu belirtmektedir. Ona 


\section{Mobil Dil Öğrenme Oyunu Uygulamalarının Tasarımında ve Seçiminde Kullanılabilecek Ölçütler Üzerine Bir Alan Taraması Çalışması}

göre bir dil öğrenme uygulaması ancak bu şekilde nihai olarak ders içeriğini destekleyici bir takviye olarak tavsiye edilmelidir.

Bu görüş, mobil dil öğrenme oyunu uygulamalarının, dil öğrenme aşamalarında kullanımı konusunda kabul görür hale gelmesi için de geçerli olacaktır. Bu yüzden her şeyden önce bir mobil dil öğrenme oyunu uygulamasının kullanıcı gözünde başarılı sayılabilmesi için öncelikle;

- kullanıcısı için ilgi çekici özelliklerinin olması,

- oyunsal özellikleri sayesinde farklı kullanıcılar ya da sanal kullanıcı ile rekabeti mümkün kılabilmesi,

- dil öğrenmekte olan kullanıcının oyun kurgusu içerisinde yeni bilgiler araştırabilmesi ve oyundaki mekânlarda serbestçe gezebilmesi gibi özellikler keşfedici bir dil öğrenme adımını teşvik etmek amaciyla tavsiye edilebilir.

Çünkü özellikle macera içerikli mobil dil öğrenme oyunu uygulamalarında öğrenicinin karşısına çıkan ve çözmesi gereken sorunlara ilişkin ipuçları ya da çözüm yolları sunulmamaktadır. Kullanıcı sorundan çıkış yolunu kendi bulmalıdır. Bunun için de öğrenmekte olduğu dilde kendisine sunulmuş olan direktifleri anlayıp uygulayarak oyunun mantığını keşfetmek durumundadır.

Funk (2010: 14) yabancı dil derslerinde kullanılması planlanan her bir medya ürününün, dersin sonucuna ne katacağı hesap edilerek öğreniciye sunulması gerektiğini düşünmektedir. Bu yüzden yabancı dil öğretim ve öğreniminde kullanılması düşünülen uygulamanın ilk etapta gerçekten sorunsuzca kullanılabilir olup olmadığının ve uygulamanın kullanımının gerçekten mantıklı olup olmadığının sorgulanması gerekmektedir. Eğer teknoloji kullanımı yabancı dil dersinde etkili bir öğrenmeye destek olmak amacıyla işe koşulmak isteniyorsa buradaki hedef, teknik imkânları öğretmenin ders içerisindeki oyuncağı haline getirmemek olmalıdır (Hugo, 1998: 67: Raun, 1984: 408). Bu yüzden öğreniciye ve ihtiyaca yönelik olarak kullanılabilir bir mobil dil öğrenme uygulaması seçmek için aşağıdaki noktaların da göz önünde bulundurulması tavsiye edilir. 


\section{Harun GÖÇERLER}

Mobil dil öğrenme oyunu uygulaması için aşağıda sıralanmış seçim ölçütleri Skoularioti'e göre dört başlıkta ele alınıp formüle edilebilir (bkz. 2013: 22):

\section{a- Genel görünüm}

- Uygulama, kullanıcının yaşına uygun olarak tasarlanmış mı?

- Uygulama basitçe yüklenebilir ve kullanılabilir mi?

- Uygulamadaki grafikler kullanıcıya hitap eden bir yapıda ve belirgin bir şekilde algilanabiliyor mu?

- Oyun, öğretmeyi hedeflediği konuyu sunuş açısından kullanıcının yaşına uygun şekilde ele alabilmiş mi?

- Soru ve oyun esnasında karşılaşılan sorunların çözümüne yönelik yardımlar mevcut mu ve bu yardım adımları gerçekten işlevsel mi?

- Oyundaki soru ve sorunların çözümüne yönelik farklı alternatif çözüm yolları belirlenmiş mi?

\section{b- İçeriksek görünüm}

- Konular ve içerikler dilin günlük kullanımı konusunda önemli rol oynuyor mu?

- Konular ve içerikler kelime bilgisinin pekiştirilmesi ve geliştirilmesine ya da farklı dil becerilerinin desteklenmesine yönelik eğitsel özelliklere sahip mi?

- Uygulama, oyunun ilerleyişi içerisinde oyuncunun oyunun geneline yönelik bütünsel bir bakış kazanacağı bağlantılara sahip $\mathrm{mi}$ ?

- İçeriklerin dilsel yapıları net ve anlaşılır mı?

- Sunulan kelimeler ve dil bilgisel yapılar konuşma, yazma, okuma ve dinleme gibi farklı dil becerilerine yönelik etkinlikler içerisinde sunuluyor mu?

\section{c- Eğitsel - metotsal görünüm}

- Uygulama keşfedici, problem çözme odaklı ve öğrenme sürecini öğrencinin kendinin belirleyebileceği bir yöntemi destekliyor mu? 
Mobil Dil Öğrenme Oyunu Uygulamalarının Tasarımında ve Seçiminde Kullanılabilecek Ölçütler Üzerine Bir Alan Taraması Çalışması

- Öğrenmeye ve uygulamayı oynamaya motive edici alıştırmalar var $\mathrm{m} 1$ ?

- Öğrenme hedefleri ve oyuncunun oyun içerisinde atacağı adımlarla ilgili görev tanımları açık ve anlaşılır bir şekilde formüle edilmiş mi?

- Hata uyarısı var mı?

- Oyun içerisindeki cümle yapıları bilginin, mesela kelime bilgisinin gerçek hayatta kullanılmasına da yardımcı olacak nitelikte mi yoksa mekanik bir görünümde mi?

\section{d- Yazılımın çoklu medya özelliklerine ilişkin noktalar}

- Farklı resim, metin ve ses kombinasyonları bir arada kullanılmış $\mathrm{mi}$ ?

- Uygulama, öğrenicinin farklı algılama kanallarına hitap ediyor mu?

- Uygulama, görsel ve akustik etkiler, animasyonlar, farklı oyunsal bileşenler ve oyun içi görevler gibi motivasyon arttırıcı alanları bir arada sunabiliyor mu?

- Çoklu medya ve oyunsal görünüm oyun içerisinde kurgulanan öğrenme süreçlerine mantıklı bir şekilde dâhil edilebilmiş mi?

Tüm bu noktaların yanında aslen kullanılması hedeflenen mobil dil öğrenme oyunu uygulamasının toplam indirilme sayısı da seçim ölçütü olarak değerlendirilebilecek önemli bir nokta olarak ele alınabilir. Çünkü bir uygulamanın toplam indirilme sayısı, söz konusu uygulamanın dünya çapında da ne kadar başarılı görüldüğü, sevildiği ve kullanıcıların ne kadarı tarafından dil öğrenimi amacıyla tercih edildiği konusunda fikir verebilir. Tabii ki bir uygulamanın ne kadar çok kullanıcı tarafından indirilmiş olduğu, öğrenicilere onun önerilmesi konusunda belirleyici bir bilimsel ölçüt olamaz. Fakat uygulama hakkında genel bir izlemin kazanmak ve uygulamanın en azından incelemeye değer olduğunu düşünmek açısından yönlendirici olabilir.

Yukarıda anılan ölçütler ışı̆̆ında bir mobil dil öğrenme oyunu uygulaması seçmeye çalışmanın asıl amacı, öğrenicilerin oyun oynarken öğrenmeyi hedefledikleri dilde karşılarına gelen görevleri teknik, dilsel, görsel ve mantıksal engeller ile karşılaşmadan çözebilmelerini sağlamaktır. Ayrıca öğreticilerin, „nasıl olsa dil 
öğrenmek ile meşguller" mantığıyla hareket ederek öğrencilerin mobil cihazlar ile saatlerce vakit geçirmelerine müsaade etmeleri bir hedef olmamalıdır. Bu yüzden, bir mobil dil öğrenme oyunu uygulamasının psikolojik temelli ve eğitsel-pedagojik bileşenleri de içinde barındıran bir yapıda kurgulanmış olmasında fayda vardır. Çünkü oyuncuyu hızlı, yoğun ve uzun süren aşamalarda öğrenmeye zorlayan ya da yönelten oyunlar, çekiciliğini de aynı hızla kaybetme tehlikesine her zaman sahiptir (Le vd., 2013: 5). Bu yüzden söz konusu oyun uygulamaları öğreniciye daha yavaş ve kısa adımlar ile oyun içerisinde yerine getirilmesi gereken somut görevler sunarak içselleşmiş bir öğrenmeyi teşvik etmelidir.

608

IJSI 14/2

Aralık

December

2021

Bu bölümde bu noktaya kadar ele alınmaya çalışılan detaylardan yola çıkarak, bir mobil dil öğrenme oyunu uygulamasından beklenebilecek bir takım genel ana noktaları dile getirmekte fayda vardır. Sonja Gabriel, mobil dil öğrenme oyunu uygulamaları ve diğer dijital dil öğrenme oyunlarında bulunması gereken genel özellikleri aşağıdaki gibi sıralamıştır.

Tablo 2: Dijital dil öğrenme oyunlarının ana özellikleri.

\begin{tabular}{|c|c|}
\hline $\begin{array}{l}\text { Oyunlar dili kullanmada } \\
\text { yaratıcılığı teşvik etmelidir }\end{array}$ & $\begin{array}{l}\text { "Doğrusal mantık ile kurgulanmış oyunlar, farklı } \\
\text { oyuncuların aynı problemin çözümüne aynı yoldan } \\
\text { ulaşmalarını hedeflerken, yeni nesil dijital oyunlar } \\
\text { doğrusal mantık içermeyen bir kurguya sahip olmalıdır. } \\
\text { Bu şekilde oyuncunun aşması gereken engeller } \\
\text { karşısında alternatif çözüm yolları bulması teşvik } \\
\text { edilebilir. Özellikle öğrenilen dilin mekanik olmayan bir } \\
\text { şekilde kullanımını gerektiren bu yaklaşım, } \\
\text { öğrenicilerin yaratıcılığını da hareketlendirecektir." }\end{array}$ \\
\hline $\begin{array}{l}\text { Oyunlar çözülmesi gereken } \\
\text { karmaşık görevler } \\
\text { içermelidir }\end{array}$ & $\begin{array}{l}\text { "Karmaşık görevler içeren oyunlar, çözüme yönelik } \\
\text { sayısız stratejik yaklaşım tarzları içerir ve bu durum da } \\
\text { öğrenilmekte olan dilde yaratıcı problem çözme } \\
\text { becerisinin gelişimine katkı sağlar." }\end{array}$ \\
\hline $\begin{array}{l}\text { Oyunlar iş birlikçi } \\
\text { öğrenmeyi teşvik etmelidir }\end{array}$ & $\begin{array}{l}\text { "Oyunda varılan sonuçlar ve oyunun öğreniciye } \\
\text { katkıları diğer dil öğrenicileri ile paylaşılabilin } \\
\text { olmalıdır. Örneğin bazı mobil dil öğrenme oyunu } \\
\text { uygulamaları oyunun aşamaları içerisinde ve oyun } \\
\text { haricinde öğreniciyi farklı sosyal } \\
\text { yönlendirmektedir. Böylece öğrenici uygulama adına } \\
\text { açılmış sosyal ağda edineceği yeni arkadaşlarla } \\
\text { öğrenmekte olduğu dilde oyun hakkıda görüs } \\
\text { alışverişinde bulunabilir. Dilin otantik kullanımın } \\
\text { deneyimleyip motive olabilir." }\end{array}$ \\
\hline
\end{tabular}

(Gabriel, 2013: 260) 


\section{Mobil Dil Öğrenme Oyunu Uygulamalarının Tasarımında ve Seçiminde Kullanılabilecek Ölçütler Üzerine Bir Alan Taraması Çalışması}

Yukarıda bir mobil dil öğrenme oyunu uygulaması seçerken dikkat edilmesi gerektiği düşünülen ölçütlerden de anlaşılacağı üzere bir çok bileşenin bir birini tamamlaması ve böylece bir çok kullanıcıya hitap edebilecek özellikte bir uygulamanın seçilebilmesi hedeflenmektedir. Günümüz dil öğrenicilerinin çoğunluğunun ve dil eğiticilerinin aslen iyi birer dijital araç kullanıcısı olduğu, fakat her zaman iyi ve hedef odaklı bir dil öğrenim uygulaması seçme konusunda gerekli eğitsel alt yapıya sahip olamayabilecekleri düşünüldügünde, sunulan ölçütlerin önemi daha iyi anlaşılabilir.

\section{SONUÇ}

Günümüzde sınıf ortamları çeşitli bilgisayar türevleriyle donatılmış dijital sistemlerle dinamik birer öğrenme-öğretme merkezlerine dönüşmektedir. $\mathrm{Bu}$ sayede öğrenme süreçleri de çeşitli sosyal formlarda farklılaşmış bir şekilde interaktif olarak gerçekleşme imkanı bulmaktadır. Bu tarz çok boyutlu, interaktif, medya güdümlü sınıf ortamları, öğrenme ve öğretme sürecinin başarılı bir şekilde yönetilmesi için önemli pedagojik hedefleri gerekli kılar. Kurumsal yapılar içerisinde sağlanması gereken bu koşullar örneğin; öğretmenin dijital medya destekli öğretme yetisine odaklanma, öğrenicilere yönelik olarak öğrenme çıtılarına odaklanma, bireyin kendinin organize edebildiği öğrenmeyi teşvik etme, tüm öğrenme süreçlerinin öğreniciye görelik ilkesine göre planlanabilmesi, yeni bir başarı ve öğrenme kültürünün teşvik edilmesi gibi ilkeler olarak siralanabilir (bkz. Baumgartner, Heber, 2013: 4).

Yeni medyaların çok yönlülüğü sadece medya araçlarının kullanımı ile sınırlı olmadığı için, bu kavram aynı zamanda insanın düşüncesinin, algısının ve eylemlerinin öğrenme süreci içerisinde yapabileceklerini de geliştirir ve çeşitlendirebilir. Bu görüşün bir adım ötesinde ise modern öğrenme teorilerine göre öğrenmenin tamamen sınıf içerisinde gerçekleşmediği savunulmaktadır. Öğrenici sınıf içerisinde zamanla dijital etmenlerin de etkisiyle öğrenme algısını çeşitlendirmeyi öğrendiği için, bu yetisini sınıf dışı öğrenme aktivitelerinde de kullanma gereksinimi duyacaktır. Dolayısıyla okulda öğrenilen bir konu okul dışında da kullanılmaz ise, söz konusu konunun olması gerektiği gibi içselleştirildiği ve öğrenenin günlük yaşamına bir davranış değişikliği olarak yansıdığı iddia edilemez. Bu sebepten, özellikle yabancı dili kendi ülkelerinde öğrenmekte olan bireyler, öğrendikleri dilsel yapıları her an gerçek 
ortamda kullanma imkânı bulamadıkları için, mümkün olduğunca dijital medya ürünlerinden faydalanmaya ve okulda öğrendiklerini en azından gerçeğe yakın öğrenme durumlarında aktif olarak kullanmaya cesaretlendirilmelidir. Bu şekilde dil öğrenicileri kendi öğrenme ihtiyaçlarına yönelik tatminkarlığı kısmen de olsa sanal öğrenme ve dil kullanım ortamlarına katılarak sağlayabilirler. Kolay erişilebilir, uygun fiyatlı, karmaşık olmayan yapıda ve her yere taşınabilir olduklarından dolayı hedef odaklı olarak seçilmiş mobil dil öğrenme oyunu uygulamalarının kullanımı yukarıda aktarılan durumdaki öğrenicilere tavsiye edilebilir.

Diğer taraftan, yenilikçi mobil cihazlar ve uygulamalar hayatımıza öğrenim zamanlarımızda herzamankinden daha çok girdiği için (bkz. Stieglitz vd., 2013: 47), özellikle mobil uygulamalar, bireysel ve sosyal öğrenmeyi de destekleyici nitelikte olduğundan dolayı eğitim alanında işlevsel olarak kullanılabileceği düşüncesiyle öğretmenler tarafından bu çalışmada ele alınan yada farklı çalışmalarda dile getirilmiş olan ölçütler çerçevesinde incelenmeli ve ihtiyaç durumuna uygun olarak öğreniciye tavsiye edilmelidir. Bunun seçimi tamamen öğreniciye bırakılmamalıdır.

Özellikle ilk yabancı dilini öğrenmekte olan insanlar kısa süre içinde, okulda öğrendikleri kelimeler ve dilbilgisel yapıları dilsel üretim aşamasında gerçekten kullanıp kullanamayacakları konusunda karamsarlığa kapılıp bu konuda kendilerince haklı sebeplerle şüpheye düşebilirler. Bu düşüncedeki dil öğrenicileri bu aşamada bir ödevi, alıştırmayı yada aktif dil kullanımı gerektiren yazılı veya sözlü iletişimsel bir problemi çözebilecekleri konusunda cesaretlendirilmeli ve kendinden emin olmaları sağlanmalıdır. Yabancı dil eğitiminde bu yaklaşım şeklini gerçek anlamda uygulamak için mobil cihazlar için geliştirilmiş modern, hedef odaklı dil öğrenme oyunları katkı sağlayabilir. Çünkü özellikle mobil dil öğrenme oyunlarında öğrenici dili sınıf içerisinde toplum karşısında kullanma kaygısı yaşamayacak, böylelikle dili kullanabildiğini önce kendine ispatlayacak ve oyun içerisindeki konu içerikleri ile geçirdiği zamanda öz güven kazanacaktır. Tabii ki bu noktada önemli olan, kullanılacak uygulamanın bu anılan becerileri destekleme özelliği olup olmadığıdır. O yüzden bir seçim yapılırken, kullanılacak olan uygulamaya gerçekten ihtiyaç duyulup duyulmadığı konusunda öncelikle öğreticilerin ikna olması ve ardından öğrenicileri ikna etmesi önemli bir unsurdur. 


\section{Mobil Dil Öğrenme Oyunu Uygulamalarının Tasarımında ve Seçiminde Kullanılabilecek Ölçütler Üzerine Bir Alan Taraması Çalışması}

Fakat durumun bu şekilde cereyan edebilmesi ve genel anlamada başarıya ulaşması için, dil öğreticileri ve eğitim kurumları gibi karar vericilerin üzerine düşen bir takım sorumluluklar da vardır. Özellikle sınıf içerisinde ve dışında hangi mobil cihazların nezaman, hangi koşullarda gerçek anlamda fayda sağlayabileceği konusunda karar verip uygulamak başta dil öğreticisinin sorumluluğu olmak üzere zamanla kurum kültürünün de bir parçası olacaktır. Biebighäuser'in de belirttiği gibi, mobil cihazların ve uygulamaların ders içerisinde kullanımı eğer gerçekten mantıklı sebep varsa mantıklı ve etkilidir (Biebighäuser, 2015: 7). Aksi takdirde bu çalışmada da ele alınmaya çalışılan ölçütlere uygun olsa da sadece bir eğlence kaynağı ve zaman geçirme aracı olmaktan ileri gidemezler.

Bu yüzden, farklı öğrenici tipleri farklı öğrenme öğretme hedeflerine ve yapılara ihtiyaç duyduğu için, bu çalışmada anılan ölçütler bir mobil dil öğrenme oyunu uygulamasının kesinlikle sahip olması gereken bir liste olarak görülmemelidir. Dolayısıyla öğreticinin seçim kriterleri de ihtiyaca göre şekillenebileceği için, yukarıda anılan ölçütler yeniden fomüle edilebilir yada güncellenebilir (bkz. Alyaz, 2003: 8). Sonuç olarak önemli olan hangi hedef ile dil öğrenme uygulamasından faydalanılmak istendiğidir. 


\section{Harun GÖÇERLER}

\section{KAYNAKÇA}

Alyaz, Yunus (2003). "Kriterien zur Evaluation von Sprachlernsoftware". Uludă̆ Üniversitesi Eğitim Fakültesi Dergisi, 16(1), 1-10.

Alyaz, Yunus (2005). "Technische Kriterien zur Evaluation von Autorensystemen für webbasiertes Sprachenlernen". Uludă̆ Üniversitesi Eğitim Fakültesi Dergisi, XVIII(2), 323-345.

Anıl, Duygu; Özkan Özer, Yeşim; Demir, Ergül (2015). PISA 2012 Araştırması Ulusal Nihai Rapor. T.C. Milli Eğitim Bakanlığı Ölçme ve Değerlendirme Sınav Hizmetleri Genel Müdürlüğü, Eğitsel Amaçlı İnternet Kullanımı. Ankara: Isskur Matbaacılık.

Bach, Mike (2012). Mobile Anwendungen mit Adroid - Entwicklung und praktischer Einsatz. München: Addison-Wesley.

Baumgartner, Peter; Herber, Erich (2013). "Höhere Lernqualität durch interaktive Medien? - Eine kritische Reflexion", Helga, B.; Walter, W. (Hrsg.). Erziehung \& Unterricht, Wien: Österreichischer Bundesverlag Schulbuch GmbH \& Co. KG, 327- 335.

Biebighäuser, Katrin (2015). “DaF-Lernen mit Apps. Zur Einleitung der Sondernummer". GFL German as a Foreign Language, 2, 1-14.

de Witt, Claudia (2015). "Mobiles Lernen. Didaktische Szenarien und technologische Möglichkeiten. Vortrag auf der ICM-Fachtagung". Marburg. https://www.youtube.com/watch?v=BQG5TVKGihM (Erişim Tarihi: 13.04.2015).

Falk, Simon (2015). “Ap(p)ropos mobil - Über den Einsatz von Apps im DafUnterricht". German as a Foreign Language, 2, 15-31.

Fogg, Jeffrey Brian (2009). "A Behavior Model for Persuasive Design". Persuasive '09 - 4th International Conference on Persuasive Technology, April 2629. Claremont, California, USA: ACM, 1-7.

Funk, Herrmann (2000). "Schnitt - Fremdsprachenunterricht zwischen "Alten" und "Neuen" Medien", Tschirner, E.; Funk, H.; Koenig, M. (Hrsg.). Schnittstellen: Lehrwerke zwischen alten und neuen Medien, Berlin: Cornelsen, 1329.

Gabriel, Sonja (2013). "Was Schule von digitalen Spielen lernen kann”, Micheuz, P.; Reiter, A.; Brandhofer, G.; Ebner, M.; Sabitzer, B. (Hrsg.). Digitale Schule- Österreich Eine analoge Standortbestimmung anlässlich der eEducation Sommertagung 2013, Graz: Österreichische Computer Gesellschaft, 259-264.

Giemza, Adam; Verheyen, Per; Philipp, Anna; Neubaum, German; Hoppe, H. Ulrich (2012). "Einsatz einer mobilen Quiz-Applikation im Schulunterricht".Desel, J., Haake, J. M.; Spannagel, C. (Hrsg.), DeLFI 2012 - 


\section{Mobil Dil Öğrenme Oyunu Uygulamalarının Tasarımında ve Seçiminde Kullanılabilecek Ölçütler Üzerine Bir Alan Taraması Çalışması}

Die 10. e-Learning Fachtagung Informatik. Hagen und Heidelberg: Gesellschaft für Informatik, 249-260.

Grüner, Margit; Hassert, Timm (1992). Einführung in den computergestützten Sprachunterricht - Fernstudieneinheit. Berlin: Langenscheidt.

Johnson, Larry; Adams, Samantha; Cummins, Michele (2012). NMC Horizon Report: 2012 Higher Education Edition: Deutsche Ausgabe. (Übersetzung: Helga Bechmann). Austin, Texas: The New Media Consortium.

Kohring, Torben (2014). Spiel- E Lernsoftware Pädagogisch beurteilt. Köln: Bundesministerium für Familie, Senioren, Frauen und Jugend.

Kolef, Inge, Anna; Rieder, Mario (1999). “Neue Medien im Sprachunterricht”. Zeitschrift für Technologie-Unterstützten Unterricht (TellECall) (1), 24-26. https://www.univie.ac.at/future.media/sprache.htm (Erişim Tarihi:21.02.2021).

Le, Son; Weber, Peter; Ebner, Martin (2013). “Game-Based Learning. Spielend Lernen?", Ebner, Martin; Schön, Sandra (Hrsg.), Lehrbuch für Lernen und Lehren mit Technologien (L3T) [Online]. http://13t.eu/homepage/das-buch/ebook2013/kapitel/o/id/120/name/game-based-learning (Erişim Tarihi: 09.02.2017).

Oberneder, Michael (2015). "Persuasive Technologien und Applikationen in Bildung und Erziehung", Lindemann, P.; Koelle, M.; Kranz, M. (Hrsg.). Persuasive Technologies and Applications - Advances in Embedded Interactive Systems Technical Report - Winter 2014/2015 (3), Passau: Embedded Interactive Systems Laboratory, 28-34.

Ostheimer, Astrid (2002). "Computerspielwelten und virtuelle Realität in der aktuellen phantastischen Literatur", Ewers, H. H.(Hrsg.). Lesen zwischen Neuen Medien und Pop-Kultur, Weinheim und München: Juventa Verlag, 163-186.

Raun, Martin (1984). “Bericht aus dem Arbeitskreis "Computer und Unterricht"”, Begemann, E. (Hrsg.). Individuelles und gemeinsames Lernen in der Schule für Lernbehinderte. Rheinland-Pfalz: Hase \& Koehler. In: Hugo, F. (1998). Computer in der Schule - Aufgaben, Möglichkeiten und Grenzen in der (Sonder-) Schule. Göppingen: Schneider Verlag Hohengehren GmbH.

Skoularioti, Erietti (2013). “neue Medien@DaF.gr - Die Mediennutzung im DaF-Unterricht an Athener Privatschulen", (Universität Wien, Institut für Deutsch als Fremd- und Zweitsprache, unveröffentlichte Magisterarbeit), Wien.

Specht, Marcus; Ebner, Martin; Löcker, Clemens (2013). "Mobiles und ubiquitäres Lernen. Technologien und didaktische Aspekte". Ebner, Martin; Schön, Sandra (Hrsg.). Lehrbuch für Lernen und Lehren mit Technologien (L3T) [Online]. 


\section{Harun GÖÇERLER}

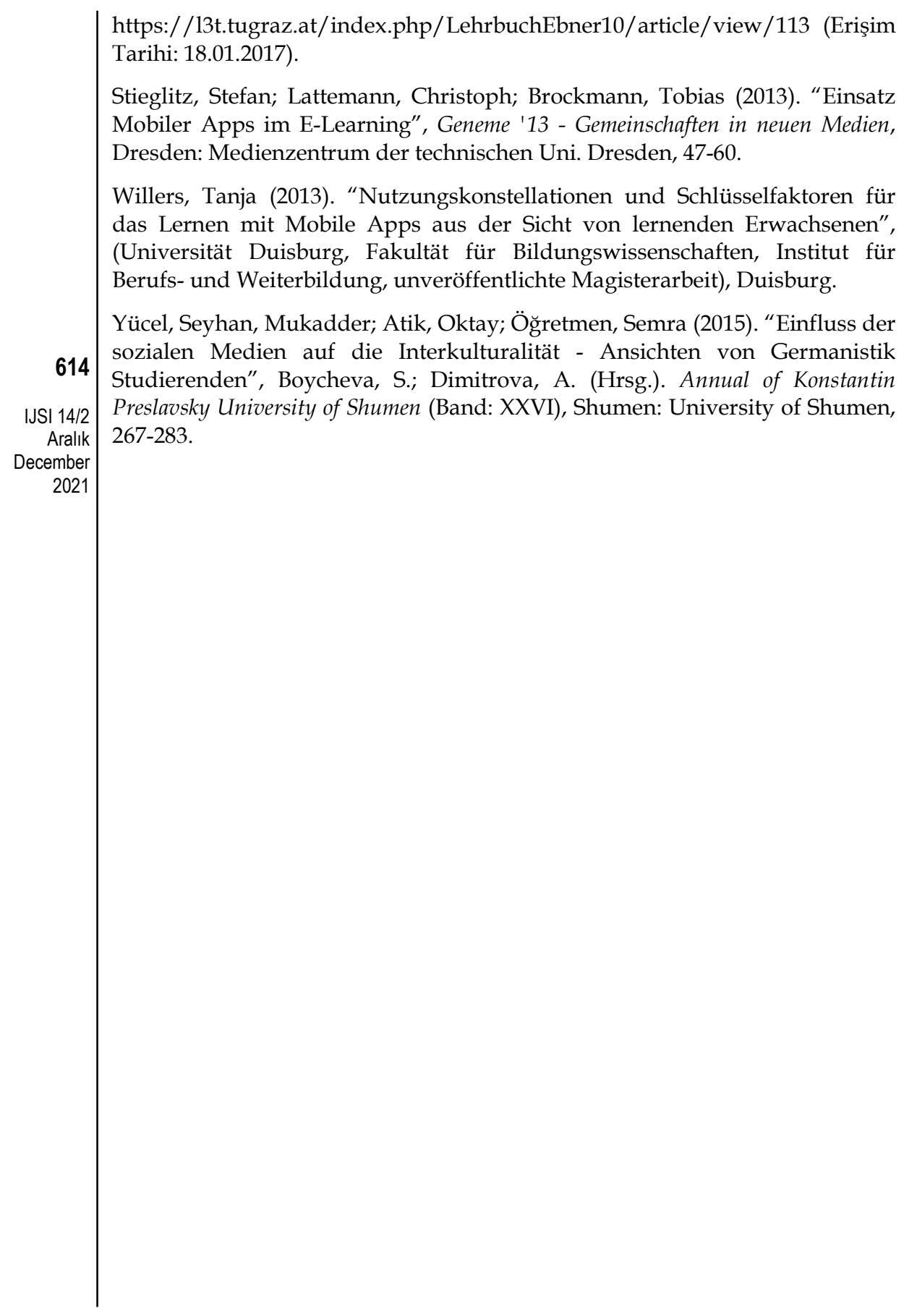




\section{Mobil Dil Öğrenme Oyunu Uygulamalarının Tasarımında ve Seçiminde Kullanılabilecek Ölçütler Üzerine Bir Alan Taraması Çalışması}

\section{SUMMARY}

Mobile applications, which are widely used in smartphones, are also encountered in foreign language education in various ways today. Mobile applications, which can be used to support the development of the skills such as reading, writing, pronunciation, listening, vocabulary, and grammar of a foreign language, have frequently been encountered as mobile language learning game applications as well, particularly since 2010 .

Mobile language learning game applications can contribute not only to the development of a single language skill but to the development of multiple language skills by creating a playful learning environment. In order for these game applications to be effective support materials, they must have an advanced setup and programming infrastructure. Otherwise, they are to take their place in the digital product garbage. When applications particularly based on language learning are taken into consideration, factors such as being able to attract the attention of the learner at first glance, the attractiveness of the graphic and visual design, an interesting and engaging game content, and the clear and sufficient instructions in the game are vital.

By conducting a literature review, the aim of this study is to reveal and discuss the general features that mobile language learning game applications should have not only for both language tutors and learners but also for application developers. As a result of the literature review, no study in this scope could be found. Before choosing the application they want to utilize in order to improve their language skills, the learners will have the opportunity to consciously find an application that is as effective as possible by considering the criteria presented in this study. Language teachers can see what they should pay attention to before choosing the support applications they recommend to their students. Application developers are likely to be the group that can benefit most from this work because the language game application they will create directly appeals to the target audience, and it is essential for them.

Taking into consideration all these points, the study aims to pose and answer questions in relation to what a mobile language learning game application should have under the headings of general appearance, content-oriented appearance, educational-methodical appearance, as well as the points about the multi-media features of the software. Games should contain complex tasks to solve, games should encourage collaborative learning, and games should encourage creativity in using the language. 
